\title{
Discourse of "Thing" as Sesotho Personal Names: A Systemic Functional Linguistics Approach
}

\author{
Masechaba M. L. Mokhathi-Mbhele \\ Department of English, National University of Lesotho, Roma Maseru, Lesotho \\ Email: masmbhele@gmail.com
}

How to cite this paper: Mokhathi-Mbhele, M.M.L. (2020) Discourse of "Thing" as Sesotho Personal Names: A Systemic Functional Linguistics Approach. Open Access Library Journal, 7: e5783.

https://doi.org/10.4236/oalib.1105783

Received: September 12, 2019

Accepted: July 26, 2020

Published: July 29, 2020

Copyright $\odot 2020$ by author(s) and Open Access Library Inc.

This work is licensed under the Creative Commons Attribution International License (CC BY 4.0).

http://creativecommons.org/licenses/by/4.0/ (c) (i) Open Access

\begin{abstract}
This paper explores the discourse of "Thing", the core element in the nominal group in Systemic Functional Linguistics (SFL) theory, when deployed as Sesotho names awarded as enacted messages. Sesotho names normally operate as authentic social discourse for they reflect real experiences embedded in these name structures. Social functions embedded in these structures elevate their significance which is embraced by socio-cultural consensus. They reflect awarders' modality or evaluation of birth contexts. This study is qualitative and data is collected from lists prepared for graduation ceremonies, employment, admission into educational institutions, neighbourhood, orphanages, telephone directories, phone-in radio programmes. The aim is to establish that Basotho use "Thing" and its dynamic forms as personal names that are socially accepted, used and revered as ancestral resemblances. The study employs form-meaning description of these names including their sub-modifications. It concludes that "Thing" reflects the interpersonal function in the field of onomastica and thus extends and strengthens the newly observed intimacy of SFL-Onomastica relationship. It contributes that deployment of "Thing" as onomastica complements its basic reference as a member of the nominal group. It also fathoms the inevitable relevance of form-meaning interdependence in describing language including onomastica. Speakers' and linguists' awareness of this interdependence is rekindled or inaugurated and name owners may develop informed meaning and pride in their names. The demeaning attitude within the word "Thing" may be eradicated by reverence of contextual adaptation. The study extends reciprocation of Phonetics, Morphology and Syntax and Semantics. The study has implications for Linguistics, Education, Media studies, Socialand Cultural studies, Journalism, Communication.
\end{abstract}




\section{Subject Areas}

Applied Linguistics

\section{Keywords}

Thing, Nominal Group, Semiotic, Interpersonal Meta-Function, Epithet,

Deictic, Numerative, Modality, Form-Meaning Interdependency,

Sub-Modifications, Attitude, Interpersonal Function, Reciprocation,

Onomastica, Ancestral Resemblances

\section{Introduction}

Names form the nominal group and in Systemic Functional Linguistics (SFL) or Systemic Functional Grammar (SFG) nominal group "consists of the noun preceded and followed by various other items all of them in some way, characterising [the noun] in question" (Halliday 2001, p. 180) [1]. In Halliday's view there occur in a certain fixed order that may occasionally permit flexibility. This is where Mokhathi-Mbhele (2014, p. 94) [2] clarifies that Sesotho personal names are noted as members of the nominal group because they reflect the logical structure of the nominal group forwarded by Halliday (2001: 180) [1]. The name Mmanthonyana [mmant ${ }^{\mathrm{h}}$ onnana] "mother of + thing + small or dainty" (mother of a small thing) has the noun $n$ tho [ $\left.\mathrm{nt}^{\mathrm{h}} \mathrm{O}\right]$ "Thing" preceded by mma [mma] "mother of ..." and followed by -nyana [nana] "small or dainty". Hussein (2011) [3] describes "There was a Saviour" using the five elements of Things in the national group, Head, Deictic, Numerative, Epithet and Quantifier and he clarifies that Dylan Thomas "employed them in different degrees in relation to the structural complexity of the nominal groups". He claims that being aware of how nominal group is structured can provide "a point of entry" for a specific literary interpretation and this view gives ways to the description of "Thing" as Sesotho personal names. Nieto (2019) [4] also presents the expansion of nominal groups in SFG and such being exposed to the principles of SFG. She claims that the exposure may empower university students to produce complex nominal groups in academic productions. Reiteration of this view in this paper guides the observed empowerment to linguists to be redirected to reveal that every language is systematically functional hence why systemic description is essential in Linguistics.

As an additional expansion, in 2014 [2] and 2016 [5] Mokhathi-Mbhele redirected the nominal group description designed for English to describe the discourse of the nominal group in Sesotho onomastica using four elements Deictic, Numerative, Epithet and Quantifier. She noted that semantic complexity essential in SFL/G permits the meanings of Sesotho names to be fused together in linguistic units as noted in Mmanthonyana [mmant ${ }^{\mathrm{h}}$ jnana] "mother of a small thing" and this view expanded the description of these elements to African lan- 
guages. The fusion is possible because as Eggins' (1996, p. 3) [6] asserts, language is semiotic, that is, "it is a conventionalized coding system, organized as sets of choices. Each choice in the system acquires its meanings against the background of the other choices made." This semiotic interpretation allows a distinction of appropriateness as against inappropriateness to be considered in relation to different linguistic choices and their un-arbitrary contexts of use. The purpose is "to view language as a resource" used by choosing meanings in contexts.

As Eggins (1996, p. 3) [6] further states, systemic grammar is "interested in language events" and this is why the intention is to describe how "Thing" is deployed as Sesotho personal name texts rendered in socio-cultural contexts that embrace real social experiences in real situations such as the birth of a baby. Though Mokhathi-Mbhele (2016) [5] has described "Thing" tributaries (deictic, numerative, quantifier, epithet) a direct description of "Thing" (Head) concept as onomastica is the focal gap that permits this study. This description presents Linguistics-Onomastica hybridity in the naming field among Basotho, encompasses the tenor (participants in a discourse, their relationships and purposes) and the mode (means used for communication to take place) that make Sesotho names enacted messages. The magnitude of awarders' positive and negative experiences and attitudes with corresponding awarders' modality (evaluation) is portrayed. Sub-modifications exclusive to Sesotho magnify the description.

\section{2. "Thing" Element in the Nominal Group in SFL}

"Thing" is described in SFL as "the functional label" (that denotes) "[the] element expressing the class of the experiential structure [in the nominal group]" (Halliday (2001, p. 180) [1]. In specific terms Halliday (2001, p. 184) [1] explains that in Systemic Functional Linguistics "Thing" may represent a "noun, a phrase or a clause". In SFL or SFG functions of language are categorised into three groups named meta-functions. Meta-functions display the language functions using SFG theory as proposed by functionalists. These three-fold meta-functions reflect meaning through the use of a clause. Thus, in this discussion "Thing" shall be described as a clause. The first meta-function identifies clause as experience (ideational), the second as exchange between participants (interpersonal), and the last actualizes clauses to form verbal messages (textual). Meta-functions exhibit social values in empirical analyses. This contributes to structure-meaning relationship experienced in the interface of language and social activity and they expose and expand the systemic network applied and exhibit value of the social values in empirical analyses, particularly of Sesotho onomastica.

\section{3. "Thing" in the Context of Sesotho Usage}

Ntho [nt ${ }^{\mathrm{h}}$ o] "Thing" is a generic Sesotho noun that names an object not specified by its name. It is classified under class 9 in Meinhof's (1977) [7] categorization of Bantu languages and authors of Sesotho grammar. In spoken interaction Baso- 
tho normally use it as a "filler deictic (a cover word)" because a speaker may unintentionally use it to fill in for a forgotten word as in mphentho ... [mp $\mathrm{m}^{\mathrm{h}} \mathrm{n}^{\mathrm{h}} \mathrm{\textrm {g }}$ ] "give me a thing" or in an expression when trying to forward a message or the speaker may intentionally use it to replace a word well understood by the interacting participants or expression but not intended for publicity.

With the last sense it is structured as "so and so" for a person or "such and such" for an object or place. In written medium it bears the meaning of the temporal medium. This is to say that it is sometimes used to carry on conversation and the speaker may select it (for convenience) when unable to identify and select the appropriate word. Though Basotho are noted as constant users of Thing' the noted styles are not exclusive to them because other African languages speakers use "Thing" with the same connotations. Some English speakers use it as well and in all these contexts it is used as a non-standard form. It is written with a small $/ \mathrm{n}-/$ and it is not used as a noun but a pronoun (not discussed in any description of Sesotho structure and function). When the initial morpheme $\mathrm{N}$ - is a capital letter but not necessarily an initiator of a sentence, Ntho [ $\mathrm{nt}^{\mathrm{h}} \mathrm{o}$ ] "Thing" becomes a personal name and is thus used as a standard form. It is this feature of a personal name that will be dwelled on in this article.

\section{Syntactic Description and Function of "Thing" As a Sesotho Personal Name and Its Extended Forms}

Ntho [nt ${ }^{\mathrm{h}}$ ] "Thing" is deployed as a personal name by Basotho. It is generally used as a family name. Mokhathi-Mbhele (2020, p. 15) [8] alerts that "Basotho have "Thing" as a personal name" thus confirming Halliday's (2001, p. 184) [1] claim that "in Systemic Functional Linguistics "Thing" may represent a "noun, a phrase or a clause". She alerts further that the description of Ntho $\left[\mathrm{nt}^{\mathrm{t}} \mathrm{o}\right]$ as a personal name is new in both the formalist and systemic functional grammars. In this description then, shall be concentrated on the structural and functional descriptions of this noun personal name. In the structural scenario, Ntho assumes various structural functions. It takes diminutive markers-terminal ana [ana] in Nthoana [ $\mathrm{nt}^{\mathrm{t}} \mathrm{wana}$ ] and forms an epithet nyana [nana] in Nthonyana [nt ${ }^{\mathrm{h}}$ onana] which functions as a derogative marker.

The diminutive feature marks size and in functional grammar description, size makes Thing an epithet. Mokhathi-Mbhele (2020, p. 14-16) [8] presents that an epithet according to Halliday (2001, p. 184) [1] is some quality of either an objective property of the thing itself or an expression of the speaker's subjective attitude towards the "Thing". Objectivity marks experiential function or meaning whereas subjectivity takes the interpersonal meaning. Experiential function is also noted as ideational and these are noted as meta-functions by Halliday. Meta-functions are manifestations in the linguistic system of three very general purposes namely ideational, interpersonal and textual, which underlie all uses of language. Experiential is concerned with experience, interpersonal takes care of social interaction between speakers within the same speech community with all 
the general features of the language in question, sounds, words, phrases, sentences, utterances, pragmatic entities observed and considered from the same view point by participants and observers. As participants interact, interpersonal function is inevitable.

The diminutive marker nyana [nana] is a clip of the small size epithet nyenyane [nejane] "small". As a marker of the diminutive form of a noun it adds diminutive feature as another contribution to the nominal group. According to Mokhathi-Mbhele (2020, p. 15) [8] Nthonyana [nt ${ }^{\mathrm{h}}$ jnana] is actually used in life to refer to a baby to show affection with the baby in its position. Parents use Nthonyana [ $\mathrm{nt}^{\mathrm{h}}$ jnana] to show concern with the small size or dainty baby.

Ntho [nt ${ }^{\mathrm{h}}$ o] may further form a personal name with a structure of the noun Ntho $\left[\mathrm{nt}^{\mathrm{h}} \mathrm{o}\right]$ followed by a qualificative to form a qualificative phrase. Such a structure would be Ntho + qualificative stem. Nthoesele "rubbish" would be formed by $N$ tho [ $\mathrm{nt}^{\mathrm{h}}$]followedbytheenumerativeesele[esele]"different".This enumerative comprises the enumerative concord $e-+$ sele [sele] which functions as an enumerative stem. esele [esele] adds to the kinds of the qualificative phrases of Sesotho as classified and described by Sesotho grammarians. According to Guma (1971, p. 104) [9] "An enumerative is a type of qualificative which is made up of any one of the concordial prefixes (low toned) ... which match with the stems -sele [sele] "different", -fe [fe] "which?" and -ngoe [nwe] "what kind" or "any".

Doke and Mofokeng $(1967,131)[10]$ ascertain that "In Bantu the enumerative denotes a category of qualificatives, miscellaneous in character, but generally having some significance of enumeration" and they reiterate the noted stems. Mokhathi-Mbhele (2006, p. 43) [11] extends observation of the socio-function of this structure as a disconcerting personal name among Basotho as observed that its translation and interpretation says "rubbish".

In another way when coining a qualificative phrase $N$ tho $\left[\mathrm{nt}^{\mathrm{h}} \mathrm{o}\right]$ may co-opt a possessive concord + stem to form an indirect possessive as exemplified by

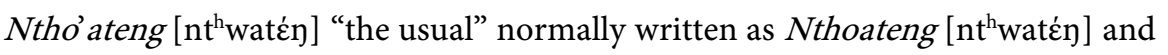
further be followed by a possessive concord + a temporal adverb in Ntho' amehla [nt ${ }^{\mathrm{h}}$ wamela] "as always" or "as expected", normally written as Nthoamehla [nt ${ }^{\mathrm{h}}$ wamela].

Ntho' amehla [ $\left.\mathrm{nt}^{\mathrm{h}} \mathrm{wamela}\right]$ and Ntho' ateng [ $\mathrm{nt}^{\mathrm{h}} \mathrm{wat}$ 'ह́ $]$ have undergone proclitic cliticization because there has been deletion of /e/ as the initial part of the possessive marker /eal "of ..." In addition, there is the descriptive feature reflected as the adverb of manner in Nthofeela [ ${ }^{\mathrm{h}}{ }^{\mathrm{h}} \mathrm{J}$ '́źla] "just a thing”. Nthoateng [nt $\left.{ }^{\mathrm{h}} \mathrm{wat} \dot{\eta}\right]$ and Nthoamehla [ $\mathrm{nt}^{\mathrm{h}}$ wamefa] allude to the norm expected though expressed in terms of time mehla [mefa] "always" and place teng [tén] "there" or

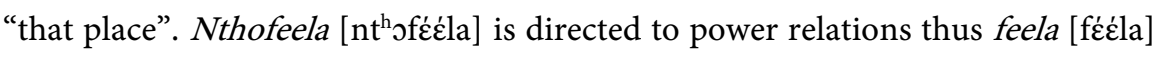
"just" describes the person within the social strata as a nonentity.

These names reflect specific Deictic features discussed by Halliday (2001, p. 181) [1] and Mokhathi-Mbhele (2016) [5] employs this view to describe Sesotho 
names with SFG deictic feature. He explains that "The Deictic element indicates or not, some specific subset of the 'Thing' is intended and if so, which. It is either 1) specific or 2) non-specific." These names Ntho' amehla [nt ${ }^{\mathrm{h}}$ wamefa] and Ntho' ateng [ $\mathrm{nt}^{\mathrm{h}} \mathrm{wat}$ ' $]$ are non-specific as they do not discreetly designate the time and place referred to. He further notes that "Thing" is specified either 1) demonstratively "by reference to ... the PROXIMITY to the speaker (this, these = near me, that, those $=$ not near me) or by 2) possessive by reference to PERSON as defined from the standpoint of the speaker (my, your, their, ... also ...'s). In these names the possessive marker explicated is ea [ja] "of ..." which could restated as the place's Thing or the time's Thing. In Halliday's (2001, p. 181) [1] words these would be subsets of Thing. Ntho amehla [nt ${ }^{\mathrm{h}}$ wamefa] and Ntho' ateng [ $\mathrm{nt}^{\mathrm{h}}$ watén] present indirect possession as the names are inscribed with the contracted possessive concord ea [ja] "of..." The employment of the possessive strengthens the nominal group feature of "Thing" in these names as the possessive is a deictic marker of "Thing". They are expressed with proclitic cliticization acceptable in the inscription of personal names with or without formal register.

In the possessive form of Sesotho the nominal member normally occurs prior to the possessive and in these names is observed that "Thing" observes this syntactic function. Thus a further new observation fathoms "Thing" with an obligatory thematic function as is the case in the described "Thing" names. They present "Thing" as the subject matter in discussion thus maintaining that these names are delegates of the nominal group.

These reflect mood in its various forms. The exclamative mood is noted in Nthoesele [nt ${ }^{\mathrm{h}}$ oesele] "rubbish" and this is a new observation in the description of SFL minor clauses. It was only noted by Mokhathi-Mbhele (2006, p. 43) [11] where she describes this name as a qualificative phrase as it conforms to the structure of a Sesotho qualificative phrase which is noun + qualificative. Declarative-exclamative mood is noted in Nthoana [nt ${ }^{\mathrm{h}}$ wana], Nthonyana [nt ${ }^{\mathrm{h}}$ jnana],

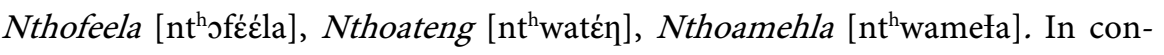
versation speakers would normally express these names preceded by the prefix $\mathrm{Ke}$ "it is ..." with a high (H) toneme and form structures such as KeNthofeela

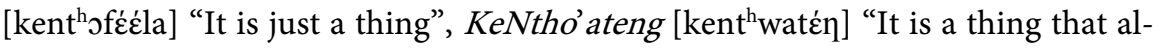
ways happens/that is expected", Kentho' amehla [kent ${ }^{\mathrm{h}}$ wamefa] "it is the usual".

This use of the prefix $k e$ "it is ..." employs the cohesive tie of ellipsis as it usually does not reflect visually but is understood in context. Its elliptic form and use also reflects prior to Nthoesele [ $\mathrm{nt}^{\mathrm{h}}$ oesele] to personify this thing from "it is ..." to be "he is ..." or it could also be an address to a second person thus being "you are ..." This address would normally be placed in parentheses because it is understood in context, that is, at times it would address a second person "you are ..." but at other times address the third person "he or she is ..."

Mokhathi-Mbhele (2016, p. 14) [5] notes that this ellipsis occurs in this name within the realm of the epithet nominal form of "Thing". In her words, "The 
bracketed "you are" in $(U)[\delta]$ Nthoesele [nt ${ }^{\mathrm{h}}$ oesele] "(you are) rubbish" is ellipsed and this feature confirms that ellipsis as a cohesive device occurs in epithet Sesotho names. This ellipsis indicates annoyance portrayed by the speaker who in this case is the name awarder." The noted ellipsis also reflects in the reduplicated form Nthontho $\left[\mathrm{nt}^{\mathrm{h}} \mathrm{on} \mathrm{t}^{\mathrm{h}} \mathrm{\rho}\right.$ ] "dainty thing" which is an aesthetic expression used exclusively as a personal name. Reduplication in Ekanjume-Ilongo's (2013, p. 1) [12] words is “... a morphological process through which the root or stem of a word [sic] or a syllable is repeated." According to Ghomesh et al. (1994, p. 309) [13] "Reduplication is the doubling up of words in speech ..." and this name concurs with this definition. This is a complete reduplication and Ekanjume-Ilongo (2013, p. 2) [12] explains that this reduplication is a complete form that is copied or repeated in its original form to build another morpheme.

Nthontho $\left[\mathrm{nt}^{\mathrm{h}} \mathrm{on} \mathrm{t}^{\mathrm{h}} \mathrm{\rho}\right]$ conforms to this explanation because the complete morpheme Ntho $\left[\mathrm{nt}^{\mathrm{h}} \mathrm{o}\right]$ presents an identical copy that finally reflects as Ntho + ntho $\left[n t^{\mathrm{h}} \mathrm{o}+n t^{\mathrm{h}} \mathrm{o}\right]$. All the segments have been repeated without alterations or additions. Thus it is neither reduced nor expanded. The repetition significantly introduces the intensity of the positive attitude of appreciation. This feature reiterates Mokhathi-Mbhele's (2020, p. 4) [14] view that reduplication in Sesotho names marks intensity.

An interesting observation in all the forwarded examples of $N$ tho $\left[\mathrm{nt}^{\mathrm{h}} \mathrm{o}\right]$ "Thing" Sesotho names is the verbless structure regardless of how long they be in structure. Mokhathi-Mbhele (2019) [8] has described these names as epithets of the nominal group. When analysing Sesotho personal names that bear an independent clause feature, Mokhathi-Mbhele (2014, p. 110) [2] discussed Sesotho names with this epithet feature. From her description these epithets describe the Subject in the nominal group. They bear the features of a descriptive word class, that being the Adjective. Such Sesotho personal names bear a non-finite or verbless structure, and such are non-specific propositions.

Eggins (2004, p. 271) [15] explains that verbless structures do not contain a verb of "saying" or "doing". In this way they are non-specific thus the action depicted is "infused". In Nthoesele [nt ${ }^{\mathrm{h}}$ oesele] "rubbish" misbehaviour or misconduct of social norms or social rules is the "infused" feature. In Nthoamehla [nt ${ }^{\mathrm{h}}$ wamefa] and Nthoateng [ $\mathrm{nt}^{\mathrm{th}}$ watén] the unspecified "usual" activity or happening is "infused". The beauty that calls for admiration in Nthoana [nt ${ }^{\mathrm{h}} \mathrm{wana}$ ], Nthonyana [ $\mathrm{nt}^{\mathrm{h}}$ onana] and Nthontho $\left[\mathrm{nt}^{\mathrm{h}} \mathrm{on} \mathrm{t}^{\mathrm{h}} \mathrm{o}\right]$ is the "infused" action in summation with corresponding actions of "saying" and "doing".

Employment of reduplication to form "Thing" name says there is cohesion in Sesotho names and in this case in the dynamics of the nominal group'. That cohesion exhibits in Sesotho names is presented by Mokhathi-Mbhele (2020, p. 2) [16]. She notes the claim by Halliday and Hasan (1978, p. 1) [17] that completeness of meaning is attained through cohesion. In their view, this cohesion produces a "unified whole" in a structure and it is the speakers who decide, on hearing or reading a structure, "whether it forms a whole or is just a collection of 
unrelated sentences". This means it thus creates discourse. That feature of a structure being a "unified whole" is capacitated by cohesion which permits the result of complete meaningful messages. This capacity creates discourse because the harboured completeness of meaning in those personal names can be cohesively comprehended (unified meaning) and therefore, can be described or interpreted as complete discourse. The reduplication displays that capacitation of a "unified whole" as the meaning extends beyond the noun $n t h o\left[\mathrm{nt}^{\mathrm{h}} \mathrm{o}\right]$.

In discourse Ntho $\left[\mathrm{nt}^{\mathrm{h}} \mathrm{o}\right]$ accommodates the affixed gender markers $R a$ - "father of ..." to form Rantho [rant ${ }^{\mathrm{h}}$ ] ] and 'M a- "mother of..." to form 'Mantho [mmant ${ }^{\mathrm{h}}$ )] which are prefixed thus to display a declarative speech function. These would refer to the biological parents of Ntho. [nt ${ }^{\mathrm{h}}$ ] Sesotho grammarians view 'Ma-[mma] "mother of ..." and $R a$ [ra] "father of ..." as prefixes that form denominative nouns. Guma (1971, p. 67) [9] defines denominative nouns as those nouns formed from other nouns. These would be classified in class 1a which specifies among other nouns, proper nouns and personal names form a sub-category of personal names. He explains further that the personal nouns in this class "must contain at least two bound morphemes, namely a noun prefix and a noun stem." These reflect in the Ntho $\left[\mathrm{nt}^{\mathrm{h}} \mathrm{o}\right]$ name as $N-+-t h o\left[\mathrm{n}+\left[\mathrm{nt}^{\mathrm{h}} \mathrm{o}\right]\right.$ as prefix + stem.

Guma (1971, p. 67) [9] continues that this set of nouns co-opts a special set of nominal prefixes "that may be affixed to form another set of nouns which are proper names of people." He refers to such nouns as denominative nouns. He explains further that "These denominative nouns are formed by prefixing $R a$ 'father of' and 'Ma 'mother of to an existing noun." Thus unto the noun Ntho [nt ${ }^{\mathrm{h}}$ ] is prefixed Ra-to form Rantho [rant ${ }^{\mathrm{h}}$ o] "father of Thing" and 'Ma to form 'Mantho [mmant ${ }^{\mathrm{h}}$ o] "mother of Thing". He notes even further that "such names often arise from the custom whereby parents adopt the name of their first-born child." There is an element of possession and this view is in consonant with the systemic view that "Thing" in the nominal as deictic has a possessive feature explicated by "of ..."

With the Sesotho version the possessor occurs prior to the "Thing" element in position and syntactic function. The name says $R a$ [ra] "father of" Ntho [nt ${ }^{\mathrm{h}}$ o] "Thing" thus forming Rantho [ $\mathrm{rant}^{\mathrm{t}} \mathrm{o}$ ]. The same recurs in 'Mantho [mmant ${ }^{\mathrm{h}}$ ] "mother of Thing". Guma emphasizes that this use with respect to parents is revered as aery polite form of address as it recognizes the parents' enhanced status in the community, the presence of the baby has awarded them a different and more respectable status revered by all community members. It would still function as a "filler cover" whereby $n t h o$ [[nt $\left.{ }^{\mathrm{h}} \mathrm{o}\right]$ may refer to that unspecified "Thing". In this case the "Thing" would, to some extend designate the baby though without a distinguishing name. This emphasizes that "Thing" strictly functions as a "filler cover" in its discourse dynamics. The affixed prefixes are significant in the dynamics of "Thing" in the nominal group and in onomastica. 
The affixation is doubled to display multi-process word formation as unto the "Thing" is simultaneous prefixing of the gender marker and the suffixation to form 'Manthoana [mmant ${ }^{\mathrm{h}}$ wana] "mother of small/dainty thing". An aesthetic feature recurs in this name because that baby referred to as "Thing" is still held with special esteem even within the address coined to refer to the parent. These names portray aninter-play of syntax and morphology but with new observations.

It is worthy to note that besides the syntactic and function features raised by the prior Sesotho grammarians, the new observations mainly raised by Mokhathi-Mbhele [2] are sub-modifications of the nominal group described by SFL theory. Halliday (2001, p. 192) [1] explains that a form that assumes character that is contrary to the norm is regarded as a sub-modification. Halliday's (2001, p. 192) [1] assertion is that when a logical structure of a nominal group is 'disturbed' that causes sub-modifications. These have an effect on the natural ordering of elements in the group and it accounts for additional elements occurring for displaced elements. Such "disturbances" are expressed in various ways in the Sesotho names. They maintain or change meanings thus maintain or change the awarders' modality.

The noted changes in the nominal group such as these diminutive suffixes, ellipsed prefixes, reduplication of $N$ tho $\left[\mathrm{nt}^{\mathrm{h}} \mathrm{O}\right]$ remind us of this term, submodification. That the gender prefixes co-exist with diminutive suffixes in affixation on "Thing" is another sub-modification. That "Thing" can be awarded to a human as a personal name and function as such to display the awarders' modality or experience is another sub-modification. According to Eggins (1996, p. 177) [6] Modality is the speaker's judgment of how likely something is or is not. Modality becomes evident in the social realm as social members interact. These "Thing" names have unearthed a new observation that 'unschooled' Basotho have been dependent on SFL theory in their naming system. In their 'field' or scenario of onomastica or personal naming they display their 'tenor' or art of interpersonal function of even employing the condescended lexicon to elevate and revere them as their mode of social interaction.

The lexemes taken to say "something is not" are reformulated to a position of stature. This is to say in social interaction, $N$ tho $\left[\mathrm{nt}^{\mathrm{h}} \mathrm{o}\right]$ proprial structures have a syntactic-semantic reference, that which Guma (1971, p. 40) [9] quotes the school of Pike on. In Guma's words, "This school admits that language is a formal system but that language is also a system of communication... with form-meaning relationships at its heart." Guma explains that the basic issue directs that form and meaning "... are so inextricably bound up that they cannot be separated from each other." Socio-functional discussion refers, therefore.

\section{Social Functions of Ntho and Its Tributary Personal Names}

In social function these names reflect interpersonal meta-function because they 
are used as forms of address between participants. The diminutive noted normally portrays a derogative character but in these names it complements the derogative diminutive displaying an aesthetic attitude. As a new observation therefore, the diminutive markers -nyana [nana] and -ana [ana] make Ntho $\left[\mathrm{nt}^{\mathrm{h}} \mathrm{o}\right.$ ] become an exhortative form of address as the speaker would be trying to entice the addressee to feel charmed and "special" and therefore comply to whatever request forwarded (if directed to an adult) and to feel loved if awarded to the baby as the baby cannot converse with the name awarder. A sense of pride is displayed in the speaker's address and it "softens" the addressee in that it builds a sense of being appreciated and unique in the eyes of the awarder. Such an attitude is intended to infect users of this name even in the community It strengthens the "social fabric" bond.

The diminutive is used to build a positive attitude of appreciation and pride as it is articulated with pride and this function complements the maintained negative function currently noted by analysts of Sesotho. Alongside the diminutive as an expression of appreciation and pride is the reduplication cohesive tie. The name Nthontho $\left[\mathrm{nt}^{\mathrm{h}} \mathrm{ont} \mathrm{t}^{\mathrm{h}} \mathrm{o}\right.$ ] is such an example. It is aesthetic in consonant with the diminutive forms Nthoana [ $\mathrm{nt}^{\mathrm{h}} \mathrm{wana}$ ] and Nthonyana. [nt ${ }^{\mathrm{h}}$ jnana] Guma (1971, p. 70) [9] presents that diminutive forms of nouns bear three significant functions namely, being markers of a reduced size or quantity corresponding to the noun in concern, the young or immature character, derogation or disparagement depending on the context and the speaker's attitude and tone. This explains why Nthoana [ $\mathrm{nt}^{\mathrm{h}}$ wana] and Nthonyana [ $\mathrm{nt}^{\mathrm{h}}$ onana] bear the aesthetic attitude. It is worthy, therefore to note that diminutive and reduplication magnify the significant features that build the "Thing" in the nominal group. This says the noted nominal group categories be complemented with reduplication and the diminutive features as they already function with the nominal group. These are new observations.

The qualificative significant in the derivation of "Thing" as a personal name in Nthoamehla [nt ${ }^{\mathrm{h}}$ wamefa] "as usual" and Nthoateng [nt ${ }^{\mathrm{h}}$ watén] "as expected" delineate an attitude of taking less recognition of the experience of the newly born at hand. The awarder would be signifying a normal expectation by society or community. It is as if an alternative of the situation at hand was not expected therefore it is an indicator of the norm. It says there is nothing exciting to look up to, there is nothing new.

Nthoesele [nt ${ }^{\mathrm{h}}$ oesele] "rubbish" is a direct insult normally awarded to the out of wedlock and the insult, though the baby's name is directed to the biological mother for her promiscuous behaviour and stubbornness when reprimanded for being truant. The awarder's summative evaluation of the situation leads him or her to coin this form. It is specific and direct and it encompasses his or her dislike of both the daughter and the innocent baby. Basotho have a saying that nonyana e otlelloa le sehlahla [nonana e otlellwa le sefafa] "when one tries to hit what is shielding in a tree or shrub the tree or shrub will inevitably suffer 
the same consequences as the target". The baby is the tree or shrub suffering the consequences of its mother's punishment for unbecoming behaviour as the name is directly borne by the baby not the biological mother. Both are understood to be nthoesele [nt ${ }^{\mathrm{h}}$ oesele] "the wrong/unwanted/not preferred/unappreciated thing" that is the "rubbish" that has disrespected the family, its norms and defied/defiled the social norms and social rules.

An alternative view could be that esele [esele] may designate "different" or exceptional'. The latter is not included in the description of Sesotho grammar but used in real context in interaction. It is more specific when attached to ntho this time the meaning of $n t h o\left[n t^{\mathrm{h}} \mathrm{o}\right]$ being an abstract character revealed in action not an object. This is to say that $n$ thoesele [ $\mathrm{nt}^{\mathrm{t}}$ oesele] would originally be a compounded lexical choice. The saying would be $o$ nthoesele [ $\delta \mathrm{nt}^{\mathrm{h}}$ oesele] "he or she is exceptional" and when this word describes an individual normally that is because the described has displayed excellence in what they did.

Ntho $\left[\mathrm{nt}^{\mathrm{h}}\right.$]becomesa"fillercover"asitencompassesthe"nitty-gritties"of the engagement and esele [esele] denotes the exceptional character. This function would be rare in relation with describing experiences of a newly born unless it is the biological father being condoned for an outstanding action he did in this baby's birth. This is to say generally this name wears a heavier measure of the negative than the positive. The ntho [nt ${ }^{\mathrm{h}}$ ] “Thing" surpasses the concrete into the abstract realm and this is yet another new observation as the prevailing descriptions are pinned onto the concrete scenario. The derivative process emanates from various angles and this inter-relates syntax and morphology.

\section{Conclusion}

"Thing" as a mire and its tributary Sesotho names extend SFL-Onomastica literature and maintain Mokhathi-Mbhele's (2014) [2] view that SFL has been employed by non-schooled Basotho in history, as displayed by their personal naming field thus legitimising SFL theory as the most appropriate theory in the description of Sesotho syntax. As observed it has been designated to describe Sesotho names as Epithets, Numerative, Quantifier and Deictic elements, and the Head form is also deployed as a Sesotho name. This SFL approach, therefore, is deemed obligatory in showcasing Sesotho form-meaning interdependence and revealing that semiotic character inherent in language. The study complements the current formalist approach as the latter overlooks the functional character of linguistic issues as they display of the interpersonal meta-function. In this meta-function is embedded the "social fabric" noted by Martin and Rose (2007) [18]. "Thing" has been deployed to make meaning by choice. SFL enhances and magnifies form-meaning description beyond the clause focused on by formalist description. The fact is that as Kotzẻ, E.and D. Kotzẻ (2002) [19] assert, words are neither innocent nor arbitrary as portrayed by "Thing" in the context of Sesotho. 


\section{Conflicts of Interest}

The author declares no conflicts of interest regarding the publication of this paper.

\section{References}

[1] Halliday, M.A.K. (2001) An Introduction to Functional Grammar. Arnold, London.

[2] Mokhathi-Mbhele, M. (2014) Independent Clause Sesotho Personal Names as Texts in Contexts. Unpublished PhD Thesis, UWC, Bellville.

[3] Hussein, K.S. (2011) A Functional Analysis of the Nominal Group Structures "There Was a Saviour" as a Case Study. http://www.researchgate.net

[4] Nieto, M. (2019) The Role of Systemic Functional Grammar in the Expansion of Nominal Group. http://www.researchgate.net

[5] Mokhathi-Mbhele, M. (2016) Sesotho Names with a Deictic Feature: A SFL Approach. Journal of Applied Linguistics and Language Research, 3, 184-193.

[6] Eggins, S. (1996) An Introduction to Systemic Functional Linguistics. Continuum, London.

[7] Meinhoff, C. (1977) Ur-bantu. Eckerdt \& Messtorff, Hamburg.

[8] Mokhathi-Mbhele, M. (2019) Epithets as Sesotho Personal Names: A Systemic Functional Linguistics Approach. Journal of Applied Language, Linguistics and Research.

[9] Guma, S.M. (1971) An Outline Structure of Southern Sotho. Shuter and Shooter, Pietermaritzburg.

[10] Doke, C.M. and Mofokeng, S.M. (1967) Textbook of Southern Sotho Grammar. Longmans Southern Africa Pty Ltd., Cape Town.

[11] Mokhathi-Mbhele, M. (2006) Sesotho Names as Qualificative Phrases. TseboJournal, 1, 42-44.

[12] Ekanjume-Ilongo, B. (2013) A Linguistic Study of Reduplication in Sesotho. Journal for Studies in Humanities, 2, 27-29.

[13] Ghomeshi, J. (2004) Contrastive Focus Reduplication in English (The Salad Salad Paper). Natural Language and Linguistic Theory, 22, 307-357.

https://doi.org/10.1023/B:NALA.0000015789.98638.f9

[14] Mokhathi-Mbhele, M. (2019) Discourse of Reduplication in Sesotho Personal Names. Unpublished Article. NUL, Roma.

[15] Eggins, S. (2004) An Introduction to Systemic Functional Linguistics. Continuum, London.

[16] Mokhathi-Mbhele, M. (2020) Cohesion in Sesotho Personal Names: A Systemic Functional Linguistics Approach. International Journal of English Language Translation Studies, 7, 87-105.

[17] Halliday, M.A.K. and Hasan, R. (1978) Cohesion in English. Longman, Essex.

[18] Martin, J.R. and Rose, D. (2007) Working with Discourse-Meaning beyond the Clause. Continuum, London.

[19] Kotzẻ, E. and Kotzẻ, D. (2002). Ethical Ways of Being. Ethics Alive, Pretoria. 